\title{
Crystal Structure and Luminescent Properties of $\mathrm{Tb}^{3+}, \mathrm{Ce}^{3+}$, and Codoped $\mathrm{NaSrPO}_{4}$ Phosphors Prepared by Microwave Sintering
}

\author{
Kun-Hsien Chen, Min-Hang Weng, ${ }^{1}$ Cheng-Tang Pan, and Ru-Yuan Yang ${ }^{2 *}$ \\ Department of Mechanical and Electro-Mechanical Engineering, National Sun Yat-Sen University, \\ Kaohsiung County 804, Taiwan \\ ${ }^{1}$ Medical Devices and Opto-Electronics Equipment Department, \\ Metal Industries Research and Development Center, Kaohsiung County 811, Taiwan \\ ${ }^{2}$ Graduate Institute of Materials Engineering, National Pingtung University of Science and Technology, \\ Pingtung County 912, Taiwan
}

(Received April 28, 2017; accepted September 7, 2017)

Keywords: phosphors, microwave processing, luminescence, $\mathrm{NaSrPO}_{4}$

A series of $\mathrm{NaSr}_{1-x-y} \mathrm{PO}_{4}: x \mathrm{~Tb}^{3+}: y \mathrm{Ce}^{3+}(x=0.04)$ phosphors doped with $\mathrm{Ce}^{3+}$ at different concentrations were synthesized by microwave-assisted sintering. The crystal structure and luminescent properties of the phosphors were carefully investigated. X-ray diffraction (XRD) analysis confirmed that all the samples were matched with the standard patterns of $\mathrm{NaSrPO}_{4}$, even though the doping concentrations of $\mathrm{Ce}^{3+}$ ions are increased to $y=0.07$. All particles prepared by microwave-assisted sintering are very nearly spherical, except at the concentration of 0.07 , at which they reveal a smooth and polygonal structure. The photoluminescence measurement shows that the major emission peak was located at $547 \mathrm{~nm}$, approximating a green luminescence, which corresponds to a ${ }^{5} \mathrm{D}_{4}$-to- ${ }^{7} \mathrm{~F}_{5}$ transition, and the optimal $\mathrm{Ce}^{3+}$ concentration, which was 0.01 , was observed. Moreover, the chromaticity $(x, y)$ is changed with increasing $\mathrm{Ce}^{3+}$ concentration.

\section{Introduction}

There are many advantages of rare-earth (RE) ion-doped phosphates as phosphors applied in near-UV LEDs, such as superior color richness, and good chemical as well as thermal stability compared with non-oxide materials. ${ }^{(1)}$ UV LEDs can generate warm white light and provide a highly efficient solid-state lighting compared with traditional common white-light LEDs (blue LED chip + yellow phosphor).

The phosphate series of phosphors with $A B \mathrm{PO}_{4}[A$ (alkaline metals) and $B$ (alkaline earth metals) are monovalent and divalent cations, respectively] compounds are considered to be ideal luminescent hosts. The rigid tetrahedral three-dimensional matrix of phosphate is considered to be ideal for charge stabilization, thus resulting in excellent thermal stability. ${ }^{(2)}$ In the past, $A B \mathrm{PO}_{4}$ compounds doped with different types of $\mathrm{RE}$ ions $\left(\mathrm{Eu}^{3+}, \mathrm{Ce}^{3+}, \mathrm{Tb}^{3+}, \mathrm{Sm}^{3+}\right.$, etc.) were frequently reported in the literature, ${ }^{(3)}$ wherein the $\mathrm{Tb}^{3+}$ and $\mathrm{Ce}^{3+}$ ions are two important $\mathrm{RE}$ ions used to generate green and blue emissions under UV excitation. Green-emitting phosphors such as $\mathrm{LaPO}_{4}{ }^{(5)}$ were obtained by utilizing a predominant ${ }^{5} \mathrm{D}_{4} \rightarrow{ }^{7} \mathrm{~F}_{5}$ transition of $\mathrm{Tb}^{3+}$ ions at around ${ }^{*}$ Corresponding author: e-mail: ryyang@mail.npust.edu.tw http://dx.doi.org/10.18494/SAM.2017.1709 
$545 \mathrm{~nm}$. A sensitizer is usually used to increase the absorption in the spectral range effectively. According to the Laporte parity selection rules, the $\mathrm{Ce}^{3+}$ ion may act as a highly efficient emission center owing to the allowed $4 \mathrm{f}-5 \mathrm{~d}$ transitions. $\mathrm{Ce}^{3+}$ is a very good candidate sensitizer for the UV-emitting $\mathrm{Tb}^{3+}$ in such phosphate lattices. ${ }^{(6-8)}$ Thus, many $\mathrm{Ce}^{3+}$ and $\mathrm{Tb}^{3+}$ codoped $A B \mathrm{PO}_{4}$ phosphors have been reported and prepared, such as $\mathrm{NaBaPO}_{4}: \mathrm{Ce} / \mathrm{Tb},{ }^{(7,9)} \mathrm{NaCaPO}_{4} \mathrm{Ce} / \mathrm{Tb}$, ${ }^{(8)}$ and $\mathrm{LiZnPO}_{4}: \mathrm{Tb} / \mathrm{Ce},{ }^{(6)}$ which encouraged us to think about the probability of the energy transfer between $\mathrm{Ce}^{3+}$ and $\mathrm{Tb}^{3+}$ in the $\mathrm{NaSrPO}_{4}$ host. The phosphors required a long sintering time to synthesize using the solid-state reaction by conventional sintering. ${ }^{(10,11)}$ However, using microwave energy as the source of the sintering process has been confirmed to improve the microstructure and properties of materials owing to different heating mechanisms. ${ }^{(12)}$ Additionally, different host materials resulting in different crystal fields and different heating mechanisms providing different energy transfer methods of the phosphors could affect the fluorescent properties of the phosphor. ${ }^{(13)}$ Novel host materials for codoping $\mathrm{Tb}^{3+}$ ions along with $\mathrm{Ce}^{3+}$ ions are important for the energy-transfer process. However, to the best of our knowledge, there are only a few reports on the research on $\mathrm{NaSrPO}_{4}: \mathrm{Ce}^{3+}$ and $\mathrm{Tb}^{3+}$ for its potential application as a green phosphor. In a previous work, we investigated the microstructural and luminescence properties of the $\mathrm{NaSrPO}_{4}: \mathrm{Tb}^{3+}$ phosphors with different $\mathrm{Tb}^{3+}$ concentrations prepared by microwave sintering. ${ }^{(14)}$ The report indicates that the optimum doping concentration of $\mathrm{Tb}^{3+}$ for $\mathrm{NaSrPO}_{4}: \mathrm{Tb}^{3+}$ phosphors is 0.04. Therefore, in this paper, we investigated and discussed the microstructure and luminescent properties of $\mathrm{NaSrPO}_{4}: \mathrm{Tb}^{3+}: \mathrm{Ce}^{3+}$ phosphors with different $\mathrm{Ce}^{3+}$ and fixed $\mathrm{Tb}^{3+}$ concentrations $(x=0.04)$ prepared by microwave sintering.

\section{Materials and Methods}

The raw materials, $\mathrm{Na}_{2} \mathrm{CO}_{3}, \mathrm{SrCO}_{3}, \mathrm{NH}_{4} \mathrm{H}_{4} \mathrm{PO}_{2}, \mathrm{~Tb}_{4} \mathrm{O}_{7}$, and $\mathrm{Ce}_{2} \mathrm{O}_{3}$ powders, all with a purity of $99.9 \%$, were stoichiometrically weighed and dispersed in alcohol followed by ball milling for $3 \mathrm{~h}$ with zirconia balls. After drying, $\mathrm{Tb}^{3+}$ - and $\mathrm{Ce}^{3+}$-doped $\mathrm{NaSr}_{1-x-y} \mathrm{PO}_{4}: x \mathrm{~Tb}^{3+}: y \mathrm{Ce}^{3+}(x=0.04$; $y=0.005,0.007,0.01,0.03,0.05$, and 0.07$)$ phosphors were synthesized by microwave-assisted sintering using a microwave furnace (Therm Wave Mod. III), with a continuously variable power of $2.45 \mathrm{GHz}$ microwaves up to $1.3 \mathrm{~kW}$.

Silicon carbide ( $\mathrm{SiC}$ ) was used as a susceptor to heat the powders indirectly due to the strong heating response to $2.45 \mathrm{GHz}$ microwaves. ${ }^{(15)}$ The material sample was placed in an $\mathrm{Al}_{2} \mathrm{O}_{3}$ crucible surrounded by four silicon carbide susceptors and encapsulated by a ceramic fiber insulating material in a microwave cavity. The mixed powders were sintered at $1200{ }^{\circ} \mathrm{C}$ for $3 \mathrm{~h}$ under an air atmosphere at $900 \pm 20 \mathrm{~W}$. The average heating rate of the microwave furnace was greater than $100^{\circ} \mathrm{C} / \mathrm{min}$.

\section{Results and Discussion}

\subsection{Structure}

Figure 1 shows the X-ray diffraction (XRD) results of the prepared $\mathrm{NaSr}_{1-x-y} \mathrm{PO}_{4}: x \mathrm{~Tb}^{3+}: y \mathrm{Ce}^{3+}$ phosphors with different $\mathrm{Ce}^{3+}$ concentrations $(x=0.04, y=0.005,0.007,0.01,0.03,0.05$, and 0.07). According to the Joint Committee on Powder Diffraction Standards (JCPDS, No. 33-1282) as a reference, all the samples are matched well with the standard patterns of $\mathrm{NaSrPO}_{4}$, even though the 


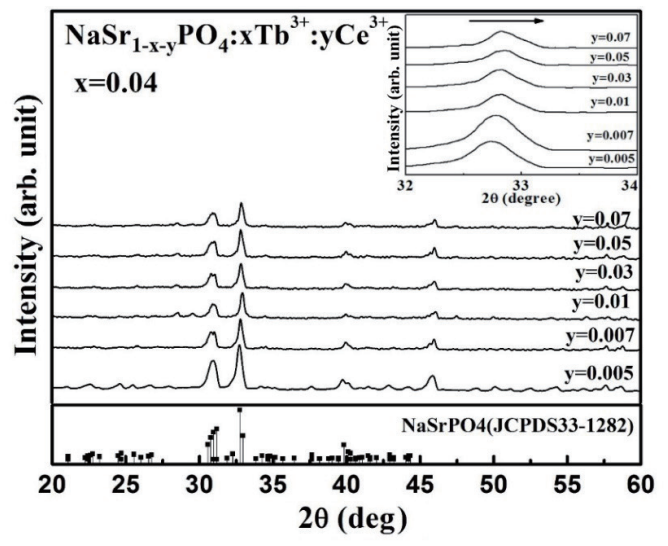

Fig. 1. XRD results of the prepared $\mathrm{NaSr}_{1-x-y} \mathrm{PO}_{4}: x \mathrm{~Tb}^{3+}: y \mathrm{Ce}^{3+}(x=0.04)$ phosphors with various concentrations of $\mathrm{Ce}^{3+}$ ions.

doping concentration of $\mathrm{Ce}^{3+}$ ions is increased to $x=0.07$. That is, the site of $\mathrm{Sr}^{3+}$ ions in $\mathrm{NaSrPO}_{4}$ phosphate can be easily replaced by $\mathrm{Tb}^{3+}$ and $\mathrm{Ce}^{3+}$ ions to form a solid solution, because $\mathrm{Sr}^{2+}$ can be replaced by $\mathrm{RE}\left(\mathrm{RE}=\mathrm{Eu}^{2+}, \mathrm{Eu}^{3+}, \mathrm{Sm}^{3+}, \mathrm{Tb}^{3+}\right.$, etc.) owing to its large size to achieve fullcolor luminescence. ${ }^{(16)}$ In addition, the JCPDS cards indicate that the $\mathrm{NaSrPO}_{4}$ host material has a standard monoclinic crystal structure in which the lattice parameters have lengths $a=2.041 \mathrm{~nm}$, $b=0.543 \mathrm{~nm}, c=1.725 \mathrm{~nm}$, and an angle $\beta=101.76^{\circ} .(17,18)$

The inset of Fig. 1 shows the enlargement of the main diffraction peak with various concentrations of $\mathrm{Ce}^{3+}$ ions. The main diffraction peak shifts slightly toward the higher angle direction $\left(32.75\right.$ to $\left.32.84^{\circ}\right)$ as the $\mathrm{Ce}^{3+}$ concentration increases because the ion radii of $\mathrm{Ce}^{3+}(1.14 \AA)$ and $\mathrm{Tb}^{3+}(1.04 \AA)$ are smaller than that of $\mathrm{Sr}^{2+}(1.29 \AA)$. The result indicates that the ion radii mismatch would cause crystal lattice distortion. ${ }^{(14)}$ In addition, the full width at half maximum (FWHM) of the X-ray diffraction peak from Scherrer's equation could be used to calculate the average crystal size $(D)$ as given by Eq. (1).

$$
D=0.9 \lambda / \omega \cos \theta
$$

where $\omega$ is the calibrated FWHM of the selected diffraction line in radians, $\theta$ is the Bragg angle, and $\lambda$ is the $\mathrm{X}$-ray wavelength $(0.15406 \mathrm{~nm})$. The crystal size $(D)$ of the $\mathrm{NaSr}_{1-x-y} \mathrm{PO}_{4}: x \mathrm{~Tb}^{3+}: y \mathrm{Ce}^{3+}(x$ $=0.04 ; y=0.005,0.007,0.01,0.03,0.05$, and 0.07 ) phosphor by microwave-assisted sintering was calculated and listed in Table 1. With increasing $\mathrm{Ce}^{3+}$ ion concentration, there is no obvious impact on the crystal size of the $\mathrm{NaSr}_{1-x-y} \mathrm{PO}_{4}: x \mathrm{~Tb}^{3+}: y \mathrm{Ce}^{3+}$ phosphors.

\subsection{Morphology}

Figure 2 shows typical SEM images of the prepared $\mathrm{NaSr}_{1-x-y} \mathrm{PO}_{4}: x \mathrm{~Tb}^{3+}: y \mathrm{Ce}^{3+}$ phosphors $(x=0.04$; $y=0.005,0.007,0.01,0.03,0.05$, and 0.07). When the $\mathrm{Ce}^{3+}$ doping concentrations were at $y=0.005$, 0.007 , and 0.01 , the average particle sizes were estimated in the range of 3-7 $\mu \mathrm{m}$. When the values were at $y=0.03,0.05$, and 0.07 , the average particle sizes were estimated in the range of 6-10 $\mu \mathrm{m}$. Although the concentration of $\mathrm{Ce}^{3+}$ ions had no obvious impact on the crystal size of 
Table 1

Average crystal size $(D)$ and color coordinates (CIE) of the prepared $\mathrm{NaSr}_{1-x-y} \mathrm{PO}_{4}: x \mathrm{~Tb}^{3+}: y \mathrm{Ce}^{3+}$ phosphors with different $\mathrm{Ce}^{3+}$ concentrations ( $x=0.04, y=0.005,0.007,0.01,0.03,0.05$, and 0.07 ).

\begin{tabular}{lcccccc}
\hline $\mathrm{Ce}^{3+}$ Concentration $(y)$ & 0.005 & 0.007 & 0.01 & 0.03 & 0.05 & 0.07 \\
\hline Crystal size $(D)(\mathrm{nm})$ & 26.8 & 26.5 & 26.4 & 26.9 & 27.4 & 27 \\
$\mathrm{CIE}(x, y)$ & $(0.21,0.23)$ & $(0.22,0.23)$ & $(0.30,0.53)$ & $(0.30,0.52)$ & $(0.27,0.44)$ & $(0.29,0.55)$ \\
\hline
\end{tabular}
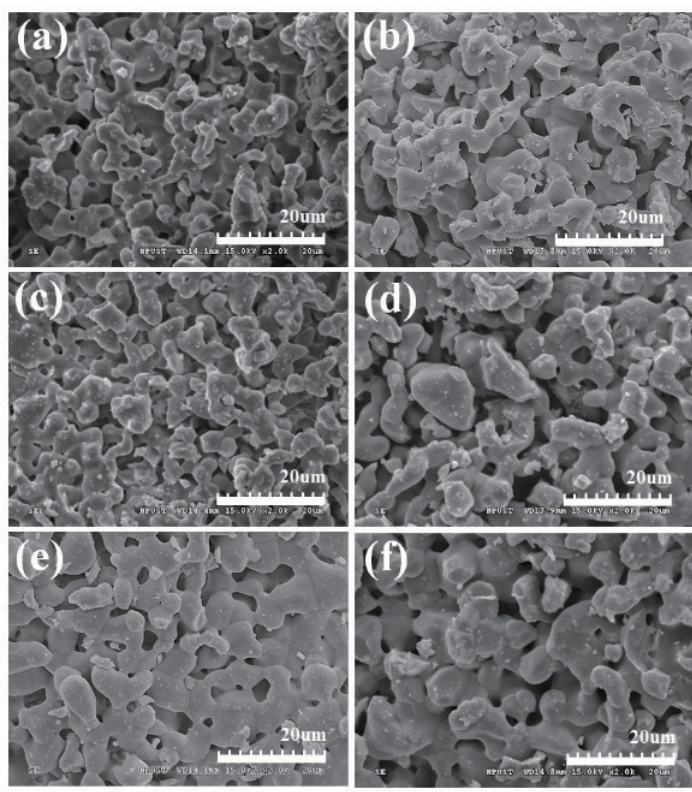

Fig. 2. SEM images of the prepared $\mathrm{NaSr}_{1-x-y} \mathrm{PO}_{4}: \mathrm{Tb}^{3+}: y \mathrm{Ce}^{3+}(x=0.04)$ phosphors with various concentrations of $\mathrm{Ce}^{3+}$ ions at (a) $y=0.005$, (b) $y=0.007$, (c) $y=0.01$, (d) $y=0.03$, (e) $y=0.05$, and (f) $y=0.07$.

the $\mathrm{NaSr}_{1-x-y} \mathrm{PO}_{4}: x \mathrm{~Tb}^{3+}: y \mathrm{Ce}^{3+}$ phosphors, the particles show high aggregation, fragmentation, and slight growth when the concentration of $\mathrm{Ce}^{3+}$ ions is increasing. The $\mathrm{Ce}^{3+}$ and $\mathrm{Tb}^{3+}$ ions were diffused into the $\mathrm{NaSrPO}^{4}$ phases readily during the calcine processes. When the concentrations of $\mathrm{Ce}^{3+}$ and $\mathrm{Tb}^{3+}$ ions increase continuously, the limit effect of the seeds will be weakened resulting in the natural growth of the phosphor particles. ${ }^{(19)}$

\subsection{Excitation and emission spectra}

Figure 3(a) shows the excitation spectrum monitored at $547 \mathrm{~nm}$ of the prepared $\mathrm{NaSr}_{1-x-y} \mathrm{PO}_{4}: x \mathrm{~Tb}^{3+}: y \mathrm{Ce}^{3+}(x=0.04)$ phosphors with various concentrations of $\mathrm{Ce}^{3+}$ ions. Several peaks in the spectral region from 200 to $400 \mathrm{~nm}$ are associated with the $\mathrm{f}-\mathrm{f}$ and $\mathrm{f}-\mathrm{d}$ transitions of $\mathrm{Tb}^{3+}$ and $\mathrm{Ce}^{3+}$ ions. The strongest peak intensity was located at $229 \mathrm{~nm}$ and the maximum value was obtained as the concentration of the $\mathrm{Ce}^{3+}$ ion is $y=0.01$, and then decreases with the increase in the $\mathrm{Ce}^{3+}$ concentration. The weaker peak intensity in the spectral region from 350 to $390 \mathrm{~nm}$ belonged to electronic-dipole-forbidden $\mathrm{f}-\mathrm{f}$ transitions of the $\mathrm{Tb}^{3+}$ ions. ${ }^{(6)}$ The Gaussian multipeak fit of the excitation spectrum of the $\mathrm{Tb}^{3+} / \mathrm{Ce}^{3+}$-doped sample is shown in the inset of Fig. 3(a). There were two Gaussian emission bands fitted into the peaks at $229 \mathrm{~nm}$, which belonged to the common absorption bands of $\mathrm{Tb}^{3+}\left({ }^{7} \mathrm{~F}_{6} \rightarrow{ }^{5} \mathrm{I}_{6}\right)$ and $\mathrm{Ce}^{3+}\left({ }^{2} \mathrm{~F}_{5 / 2} \rightarrow{ }^{5} \mathrm{~d}\right)$. One centered at 223 $\mathrm{nm}\left[\mathrm{Ce}^{3+}\left({ }^{2} \mathrm{~F}_{5 / 2} \rightarrow{ }^{5} \mathrm{~d}\right)\right]$, and the other peak centered at $231 \mathrm{~nm}\left[\mathrm{~Tb}^{3+}\left({ }^{7} \mathrm{~F}_{6} \rightarrow \mathrm{I}_{6}\right)\right] .{ }^{(7)}$ However, the wavelength of the excitation peak is $229 \mathrm{~nm}$, which is slightly shorter than the peak of $266 \mathrm{~nm}$ 


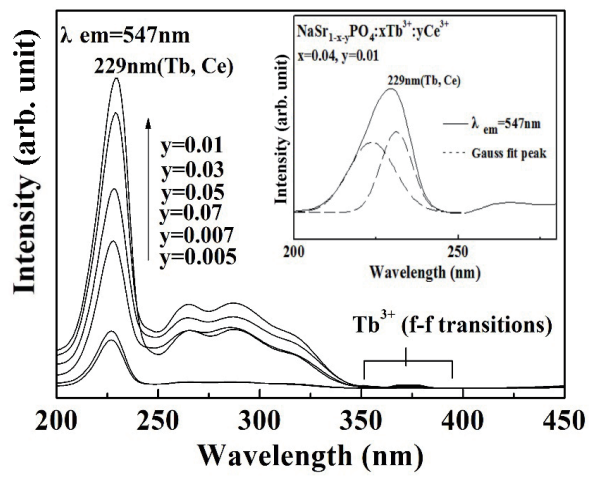

(a)

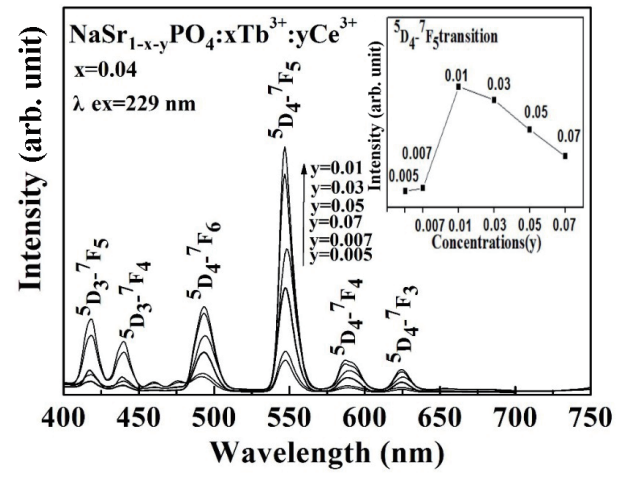

(b)

Fig. 3. (a) Excitation spectra and (b) emission spectra of the prepared $\mathrm{NaSr}_{1-x-y} \mathrm{PO}_{4}: x \mathrm{~Tb}^{3+}: y \mathrm{Ce}^{3+}(x=0.04)$ phosphor with various concentrations of $\mathrm{Ce}^{3+}$ ions. The inset of Fig. 3(b) shows the emission intensity at the wavelength of $546 \mathrm{~nm}$ from various concentrations of $\mathrm{Ce}^{3+}$ ions.

reported by Cheng et al. ${ }^{(1)}$ A sensitizer is used to transfer the excitation energy to the RE activator by exciting an optically allowed transition resulting in high light output. A well-known example is the sensitizer of $\mathrm{Ce}^{3+}$ from the broad to the narrow-line $\mathrm{Tb}^{3+}$ activator due to the nearest neighbors in the crystal lattice and optimal spectral overlap. ${ }^{(20)}$ However, the structure of $\mathrm{NaSrPO}_{4}$ is related to the $\beta-\mathrm{K}_{2} \mathrm{SO}_{4}$ type and belongs to the monoclinic system. Therefore, $\mathrm{NaSrPO}_{4}$ has three different $\mathrm{Na}$ sites ( $\mathrm{Na} 1, \mathrm{Na} 2$, and $\mathrm{Na} 3$ ) and three different $\mathrm{Sr}$ sites ( $\mathrm{Sr} 1, \mathrm{Sr} 2$, and $\mathrm{Sr} 3$ ) in the lattices in comparison with the same $\beta-\mathrm{K}_{2} \mathrm{SO}_{4}$ type structure of $\mathrm{KBaPO}_{4}$, which belongs to the orthorhombic system. ${ }^{(21)}$ In such disordered multisite structure of $\mathrm{NaSrPO}_{4}$ codoped with $\mathrm{Ce}^{3+} / \mathrm{Tb}^{3+}$ ions, the excitation energy could distribute in a different way from the various sites so that the excited range would be affected owing to the different host structure surrounding the $\mathrm{Tb}^{3+} / \mathrm{Ce}^{3+}$.

Figure 3(b) shows the emission spectra of the prepared $\mathrm{NaSr}_{1-x-y} \mathrm{PO}_{4}: x \mathrm{~Tb}^{3+}: y \mathrm{Ce}^{3+}(x=0.04)$ phosphors with various concentrations of $\mathrm{Ce}^{3+}$ ions. There are six emission transitions in the range of $400-650 \mathrm{~nm}$, and the strongest emission band is located at $546 \mathrm{~nm}\left({ }^{5} \mathrm{D}_{4} \rightarrow{ }^{7} \mathrm{~F}_{5}\right)$. The emission peaks originate from ${ }^{5} \mathrm{D}_{3} \rightarrow{ }^{7} \mathrm{~F}_{J}(J=4,5)$ such as $5 \mathrm{D}_{3} \rightarrow 7 \mathrm{~F}_{5}(418 \mathrm{~nm})$ and ${ }^{5} \mathrm{D}_{3} \rightarrow{ }^{7} \mathrm{~F}_{4}(440 \mathrm{~nm})$, and ${ }^{5} \mathrm{D}_{4} \rightarrow{ }^{7} \mathrm{~F}_{J}(J=3,4,5,6)$ such as ${ }^{5} \mathrm{D}_{4} \rightarrow{ }^{7} \mathrm{~F}_{6}(493 \mathrm{~nm}),{ }^{5} \mathrm{D}_{4} \rightarrow{ }^{7} \mathrm{~F}_{5}(547 \mathrm{~nm}),{ }^{5} \mathrm{D}_{4} \rightarrow{ }^{7} \mathrm{~F}_{4}(587 \mathrm{~nm})$, and ${ }^{5} \mathrm{D}_{4} \rightarrow{ }^{7} \mathrm{~F}_{3}(625 \mathrm{~nm})$. The emissions of ${ }^{5} \mathrm{D}_{3} \rightarrow{ }^{7} \mathrm{~F}_{J}(J=4,5)$ transitions are much weaker than those of ${ }^{5} \mathrm{D}_{4} \rightarrow{ }^{7} \mathrm{~F}_{J}(J=3,4,5,6)$, owing to cross-relaxation, which is a one-step transfer of part of the energy from excited donors to acceptors. ${ }^{(7,14)}$ The emission spectrum of the $\mathrm{Tb}^{3+} / \mathrm{Ce}^{3+}$-doped phosphor consists of two parts. One is the weak blue emission below the wavelength of $450 \mathrm{~nm}$, originating from the relaxation of the ${ }^{5} \mathrm{D}_{3} \rightarrow{ }^{7} \mathrm{~F}_{J}(J=4,5)$ transitions. The other is the strong yellowish green and red emissions above the wavelength of $450 \mathrm{~nm}$, originating from the relaxation of the ${ }^{5} \mathrm{D}_{4} \rightarrow{ }^{7} \mathrm{~F}_{J}(J=3,4,5,6)$ transitions. The intensity at the wavelength of $547 \mathrm{~nm}$ from the ${ }^{5} \mathrm{D}_{4} \rightarrow{ }^{7} \mathrm{~F}_{5}$ transition was slightly increased by changing the codoping concentration of the $\mathrm{Ce}^{3+}$ ion. It is difficult to distinguish the peak intensity contributed by the $\mathrm{Ce}^{3+}$ or $\mathrm{Tb}^{3+}$ due to overlap. ${ }^{(22)}$

The inset of Fig. 3(b) shows the emission intensity at the wavelength of $547 \mathrm{~nm}$ obtained from various concentrations of $\mathrm{Ce}^{3+}$ ions. It reaches a maximum value when the concentration of the $\mathrm{Ce}^{3+}$ ion is 0.01 and then concentration quenching occurred. When the activator and sensitizer occupy adjacent lattice sites, the wave functions of the sensitizer and activator could overlap to exchange electronics, and then the mechanism of exchange interaction could be induced by the energy transfer. ${ }^{(14)}$ 
The mechanism of energy transfer was proposed by Blasse ${ }^{(23)}$ and calculated using the concentration quenching method describing the critical energy transfer distance $\left(R_{C}\right) . R_{C}$ for energy transfer between the host lattice, activator, and sensitizer and the critical distance was estimated as ${ }^{(24)}$

$$
R_{C} \approx 2\left(\frac{3 V}{4 \pi X_{C} N}\right)^{1 / 3}
$$

where $V$ is the volume of the unit cell, $X_{C}$ is the total concentration of $\mathrm{Tb}^{3+}$ and $\mathrm{Ce}^{3+}$ ions, and $N$ is the number of formula unit per unit cell. For the $\mathrm{NaSrPO}_{4}$ host, $N=16, X_{C}=0.05,0.04$ (without $\mathrm{Ce}^{3+}$ ion), and $V=1.87121 \mathrm{~nm}^{3}$. According to Eq. (2), the critical distance $\left(R_{C}\right)$ of the $\mathrm{NaSr}_{1-x-y} \mathrm{PO}_{4}: x \mathrm{~Tb}^{3+}: y \mathrm{Ce}^{3+}(x=0.04, y=0.01)$ phosphor was calculated to be about $1.65 \mathrm{~nm}$, which is less than that obtained without $\mathrm{Ce}^{3+}$ ion doping $(1.77 \mathrm{~nm})$. The critical distance between the activator and the sensitizer becomes smaller as the concentration of $\mathrm{Ce}^{3+}$ ions was increased owing to the overlap of the wave functions of the sensitizer and activator. Moreover, according to Dexter's theory, the energy transfer mechanism resulted from the nonradioactive interaction among the activator and the sensitizer. ${ }^{(25)}$

\subsection{Commission International de l'Eclairage (CIE) 1931 chromaticity}

In general, color can be expressed by means of color coordinates and the CIE 1931, which is a two-dimensional graphical representation of any color perceptible by the human eye on an $x-y$ plot. Therefore, all the results calculated from Fig. 3(b) were drawn in the CIE 1931 chromaticity diagram as shown in Fig. 4. The chromaticity $(x, y)$ is changed with increasing $\mathrm{Ce}^{3+}$ concentration and the values are listed in Table 1.

The result indicates that the chromaticity coordinates of the $\mathrm{NaSr}_{1-x-y} \mathrm{PO}_{4}: x \mathrm{~Tb}^{3+}: y \mathrm{Ce}^{3+}(x=0.04)$ phosphors with various concentrations of $\mathrm{Ce}^{3+}$ ions have a very large shift range from blue to green. Therefore, by tuning the $\mathrm{Ce}^{3+}$ doping concentration, the $\mathrm{NaSr}_{1-x-y} \mathrm{PO}_{4}: x \mathrm{~Tb}^{3+}: y \mathrm{Ce}^{3+}(x=0.04)$ phosphors could have different color applications.

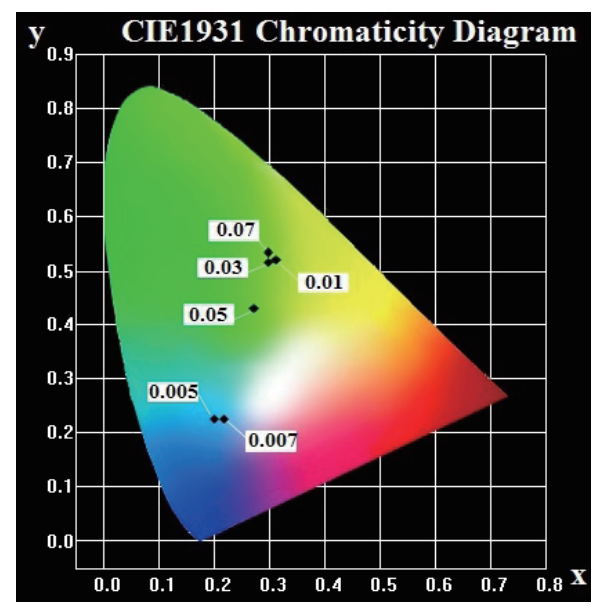

Fig. 4. (Color online) CIE 1931 chromaticity diagram of the prepared $\mathrm{NaSr}_{1-x-y} \mathrm{PO}_{4}: x \mathrm{~Tb}^{3+}: y \mathrm{Ce}^{3+}(x=0.04)$ phosphors with various concentrations of $\mathrm{Ce}^{3+}$ ions. 


\section{Conclusions}

In summary, we have successfully synthesized $\mathrm{NaSr}_{1-x-y} \mathrm{PO}_{4}: x \mathrm{~Tb}^{3+}: y \mathrm{Ce}^{3+}(x=0.04 ; y=0.005$, $0.007,0.01,0.03,0.05$, and 0.07 ) phosphors using microwave sintering at $1200{ }^{\circ} \mathrm{C}$ for $3 \mathrm{~h}$ in air atmosphere. The XRD results showed that with increasing doping concentration of the $\mathrm{Ce}^{3+}$ ions, the crystal structure of $\mathrm{NaSrPO}_{4}$ does not change and remains to be a single phase, but the diffraction peak shifts slightly toward the higher angle direction ( 32.75 to $32.84^{\circ}$ ) owing to the smaller $\mathrm{Ce}^{3+}$ and $\mathrm{Tb}^{3+}$ ion radii than that of $\mathrm{Sr}^{2+}$. With increasing $\mathrm{Ce}^{3+}$ ion concentration, there is no obvious impact on the crystal size of the $\mathrm{NaSr}_{1-x-y} \mathrm{PO}_{4}: x \mathrm{~Tb}^{3+}: y \mathrm{Ce}^{3+}$ phosphors from the XRD results. However, the particles show high aggregation, fragmentation, and slight growth when the concentration of the $\mathrm{Ce}^{3+}$ ions is increasing because the limit effect of the seeds will be weakened resulting in the natural growth of the phosphor particles during the calcine processes. Owing to the disordered multisite structure of $\mathrm{NaSrPO}_{4}$ codoped by $\mathrm{Ce}^{3+} / \mathrm{Tb}^{3+}$ ions, the excitation energy could distribute in a different way from the various sites so that the wavelength of the excitation peak of the $\mathrm{NaSr}_{1-x-y} \mathrm{PO}_{4}: x \mathrm{~Tb}^{3+}: y \mathrm{Ce}^{3+}$ phosphor is also located in the UV range, and not to transfer the excitation energy to the $\mathrm{Tb}^{3+}$ activator by exciting an optically allowed transition of $\mathrm{Ce}^{3+}$. As $\mathrm{NaSr}_{1-x-y} \mathrm{PO}_{4}: x \mathrm{~Tb}^{3+}: y \mathrm{Ce}^{3+}$ phosphors were excited at $229 \mathrm{~nm}$, the highest emission peak intensities were located at $547 \mathrm{~nm}$ as the concentration of $\mathrm{Ce}^{3+}$ was increased to 0.01 and then concentration quenching occurred. Moreover, the calculated $R_{C}$ value was approximately $1.65 \mathrm{~nm}$ and became smaller as the concentration of $\mathrm{Ce}^{3+}$ ions was increased owing to the overlap of the wave functions of the sensitizer and activator from the nonradiative energy transfer mechanism, thereby improving the photoluminescence properties of the $\mathrm{NaSrPO}_{4}: \mathrm{Tb}^{3+}$ phosphor. Finally, the chromaticity $(x, y)$ is changed with increasing $\mathrm{Ce}^{3+}$ concentration. Therefore, by tuning the $\mathrm{Ce}^{3+}$ doping concentration, the $\mathrm{NaSr}_{1-x-y} \mathrm{PO}_{4}: x \mathrm{~Tb}^{3+}: y \mathrm{Ce}^{3+}(x=0.04)$ phosphors could have different color applications.

\section{Acknowledgments}

This study was funded by the Ministry of Science and Technology, Taiwan, R.O.C. under contract No. MOST 105-2622-E-110-009-CC2. The authors would also like to thank the National Nano-Device Laboratories and the Precision Instrument Center of National Pingtung University of Science and Technology for supplying experimental equipment.

\section{References}

1 S. D. Cheng, C. H. Kam, and S. Buddhudu: Mater. Res. Bull. 36 (2001) 1131.

2 Y. K. Su, Y. M. Peng, R. Y. Yang, and J. L. Chen: Opt. Mater. 34 (2012) 1598.

3 Z. C. Wu, J. Liu, and M. L. Gong: Chem. Phys. Lett. 466 (2008) 88.

4 Z. P. Yang, G. W. Yang, S. L. Wang, J. Tian, X. N. Li, Q. L. Guo, and G. S. Fu: Mater. Lett. 62 (2008) 1884.

5 V. Pankratov, A. I. Popov, A. Kotlov, and C. Feldmann: Opt. Mater. 33 (2011) 1102.

6 C. M. Ouyang, S. Ma, Y. Rao, X. M. Zhou, X. Z. Zhou, and Y. X. Li: J. Rare Earth 30 (2012) 637.

7 J. Y. Sun, X. Y. Zhang, Z. G. Xia, and H. Y. Du: J. Electrochem. Soc. 158 (2011) J368.

8 N. Guo, Y. H. Song, H. P. You, G. A. Jia, M. Yang, K. Liu, Y. H. Zheng, Y. J. Huang, and H. J. Zhang: Eur. J. Inorg. Chem. 29 (2010) 4636.

9 X. H. Dou, W. R. Zhao, E. H. Song, L. L. Deng, X. B. Fang, and H. C. Min: J. Rare Earth. 30 (2012) 739.

10 J. Dhanaraj, R. Jagannathan, T. R. N. Kutty, and C. H. Lu: J. Phys. Chem. B 105 (2001) 11098.

11 W. J. Park, M. K. Jung, T. Masaki, S. J. Im, and D. H. Yoon: Mater. Sci. Eng. B 146 (2008) 95.

12 R. Y. Yang, H. Y. Chen, C. M. Hsiung, and S. J. Chang: Ceram. Int. 37 (2011) 749.

13 Y. M. Peng, Y. K. Su, and R. Y. Yang: Proc. 2012 Active-Matrix Flatpanel Displays and Devices Conf. (AM-FPD '12) p. 87. 
14 K. H. Chen, M. H. Weng, C. T. Pan, and R. Y. Yang: Powder Technol. 288 (2016) 117.

15 P. D. Ramesh, D. Brandon, and L. Schachter: Mater. Sci. Eng. A 266 (1999) 211.

16 C. C. Lin, R. S. Liu, Y. S. Tang, and S. F. Hu: J. Electrochem. Soc. 155 (2008) J8.

17 Y. L. Tung and J. H. Jean: J. Am. Ceram. Soc. 92 (2009) 1860.

18 R. Y. Yang, C. T. Pan, K. H. Chen, and C. Y. Hung: Opt. Mater. 35 (2013) 2183.

19 Y. Pu, K. Tang, D. C. Zhu, T. Han, C. Zhao, and L. L. Peng: Nano-Micro Lett. 5 (2013) 117.

20 M. T. Jose and A. R. Lakshmanan: Opt. Mater. 24 (2004) 651.

21 S. Zhang, Y. Nakai, T. Tsuboi, Y. Huang, and H. J. Seo: Inorg. Chem. 50 (2011) 2897.

22 K. Y. Jung and H. W. Lee: J. Lumin. 126 (2007) 469.

23 G. Blasse: Philips Res. Rep. 24 (1969) 131.

24 Z. C. Wu, J. X. Shi, J. Wang, and M. L. Gong: J. Solid State Chem. 179 (2006) 2356.

25 D. L. Dexter: J. Chem. Phys. 21 (1953) 836.

\section{About the Authors}

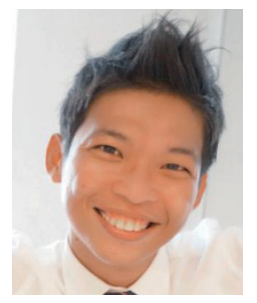

Kun-Hsien Chen received his B.S. and M.S. degrees from Kun Shan University, Taiwan, in 2007 and 2009, respectively, and his Ph.D. degree from National Sun Yat-Sen University, Taiwan, in 2016. His research interests are in LED phosphors and solar cells.

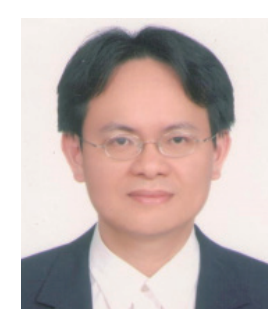

Min-Hang Weng received his B.S., M.S., and Ph.D. degrees from National Cheng Kung University, Taiwan, in 1994, 1996, and 2000, respectively. From 2000, he was a researcher at a legal foundation in Taiwan. His research interests are in RF filters, solar cells, and LED phosphors.

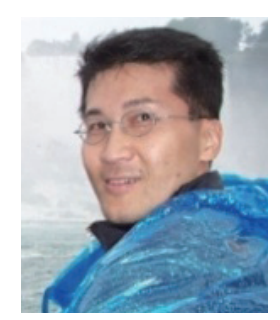

Cheng-Tang Pan received his M.S. and Ph.D. degrees from National Tsing Hua University, Taiwan, in 1993 and 1998, respectively. Since 2008, he has been a professor at National Sun Yat-Sen University, Taiwan. His research interests are in MEMS, LIGA-like processes, and LED phosphors.

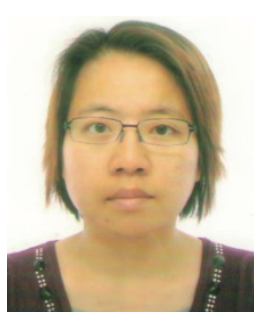

Ru-Yuan Yang received her B.S. degree from National Taiwan Normal University, Taiwan, in 1996, her M.S. degree from National Sun Yat-Sen University, Taiwan, in 2000, and her Ph.D. degree from National Cheng Kung University, Taiwan, in 2007. Since 2014, she has been a professor at National Pingtung University of Science and Technology, Taiwan. Her research interests are in LED phosphors, solar cells, and semiconductor processes. 